Let us write as follows the equations for the three variables $x, y, z$.

$$
\begin{gathered}
z=\frac{a}{\sigma \sqrt{2 \pi}} e^{-x^{2} / 2 \sigma^{2}}, . \\
y=\int_{0}^{x} z d x .
\end{gathered}
$$

In the above-mentioned paper it is shown that the equation

$$
z=k\left(\frac{a^{2}}{4}-y\right)^{0.8111}
$$

gives a very close approximation to the values taken from a Probability Integral Table. The numerical value of $k$ may be computed from

$$
k \sigma=\frac{\mathrm{I} \cdot 23 \mathrm{I} 8}{a^{0} \cdot \overline{6} 222} \text {. }
$$

Now, eliminating $z$ from equations (I) and (3) :

$$
\begin{gathered}
y=\sqrt{\frac{a^{2}}{4}-10^{2}, .} \\
u=\log _{10} \frac{a^{2}}{4}-0.2677\left(\frac{x}{\sigma}\right)^{2} .
\end{gathered}
$$

\begin{tabular}{|c|c|c|c|c|c|}
\hline \multicolumn{3}{|c|}{ From Prob. Integral Table. } & From (3). & From (5). & Plummer's. \\
\hline 0.0 & $\begin{array}{c}z . \\
398 \cdot 9\end{array}$ & $\begin{array}{c}y . \\
o\end{array}$ & $\begin{array}{c}z . \\
40 O \cdot I\end{array}$ & $\begin{array}{l}y . \\
\mathrm{o}\end{array}$ & $y$. \\
\hline 0.5 & $352 \cdot \mathrm{I}$ & I9I.5 & $35 \mathrm{I} \cdot 8$ & I $89^{\circ} 0$ & I $9 \mathrm{I} \cdot 5$ \\
\hline 1.0 & $242 \cdot 0$ & $34 \mathrm{I} \cdot 3$ & $240 \cdot 6$ & $339^{\circ} 2$ & $342 \cdot 0$ \\
\hline $\mathrm{I} \cdot 5$ & 129.5 & $433 \cdot 2$ & $129 \cdot 7$ & $433 \cdot \mathrm{I}$ & $435 \cdot \mathrm{I}$ \\
\hline $2 \cdot 0$ & $54^{\circ} \mathrm{O}$ & $477 \cdot 3$ & $56 \cdot 3$ & $478 \cdot 3$ & $478 \cdot 8$ \\
\hline $2 \cdot 5$ & 17.5 & $493 \cdot 8$ & 19.9 & $494 \cdot 7$ & $488 \cdot 4$ \\
\hline $3 \cdot 0$ & 4.4 & $498 \cdot 6$ & $5 \cdot 6$ & $499^{\circ} \mathrm{o}$ & $\ldots$ \\
\hline $3 \cdot 5$ & 0.9 & $499 \cdot 8$ & $I \cdot 3$ & $499 \cdot 9$ & . \\
\hline
\end{tabular}

Putting $a=1000$, the following Table shows the degree of accuracy of the equations (3), (5), and of Prof. Plummer's formula.

Prof. Plummer's formula may be used only up to $x / \sigma=\sqrt{\sigma}=2.449$ (see NATURE of October 25). It is simpler than equation (5), and is to be preferred whenever values of $y$ are quickly wanted for small values of $x$. However, in practical statistical work, problems may arise requiring one of the variables $x, y, z$ to be determined in terms of one of the other two over the whole of the range of $x$. For such cases, when great accuracy is not wanted, the above equations may be useful to replace Probability Integral Tables. The variable $x$ may be computed in terms of $y$ from equations (I) and (3).

Physical Department, Cairo.

S. KRICHEWSKY.

November 22.

\section{The Word "Scientist" or its Substitute.}

I Do not think exception can fairly be taken to the adoption into a living language of any word that (I) contributes to convenient expression and (2) violates no rule or custom in etymology. Contemporary speech has this advantage over a dead language as a vehicle of thought, that it can be adapted to changing circumstance, whether that be effected by modifying the meaning of old vocables or by the addition of new ones. The invention of printing did much to arrest colloquial change and to standardise speech, but a useful measure of elasticity

1 The exponent of equation ( 3 ) has been previously given as $=0.7864$ and has been recently corrected to $0.8 \mathrm{IIIr}$ by more rigorous methods. Equation (4) has been correspondingly corrected. still prevails. Examples in point are the verbs " to burke " and " to boycott," which it would be very inconvenient to discard.

It has been pointed out by correspondents in NATURE that there is plenty of analogy in sound English for the formation of "scientist" from " science." Sir E. Ray Lankester objects to the term because there is no precise definition of science; but surely we all know what is meant by a "man of science," for which term "scientist " seems a neat synonym, standing aptly in antithesis to "sciolist"one who has a smattering of some branch of knowledge.

Monreith, Whauphill, Herbert Maxwell.

Wigtownshire.

WRITING as a student of the history of words, "scientist" can never become a permanent part of any language, for its quantity is "impossible." It has a destructive effect in a sentence, and when spoken the last syllables must be gobbled. " Naturalist" may be gobbled fairly easily; few people notice it ; but "scientist" is difficult. So perhaps it scarcely matters whether the word receives or not the approval of the dictionaries; words which we instinctively feel are repulsive drop out of use.

The only possible salvation for the word is for its advocates to introduce the more correct pronunciation "sciéntist," that is, middle syllable accented. Thesist, logist, are alternatives which suggest themselves; the latter would be in conformity with "biology" and the many other " logy's."

45 Waban Hill Road, Reginald A. Fessenden. Chestnut Hill, Mass., December I 5 .

\section{The Spectrohelioscope.}

I AM very glad to learn from NATURE of November 8, p. 683 , that Mr. F. Stanley is also engaged in developing a spectrohelioscope. In my long focus ( 13 feet) instrument, where the slits are rather narrow and hence close together in order to give sufficient light with the requisite purity, the motion of the spectral line is practically equal to that of the slit for the small displacements from the optical axis involved. Thus it is possible to avoid the use of such deflecting prisms and gearing as Mr. Stanley employs. I have not yet attempted, however, to design a short focus instrument.

A rotating disc with radial slits makes a natural appeal to the instrument designer and I used it for my first (unsuccessful) experiments, made on Mount Wilson with the 30 -foot spectroscope of the 6o-foot tower telescope many years ago. It will serve very well with a moderate number of slits when there is sufficient light, but the high purity required for observations of the hydrogen flocculi complicates the problem. For example, in order to obtain with a disc the purity and brightness I now command with an oscillating bar (carrying two sets of five slits each), it would be necessary to use about 400 radial slits, each 0.003 inch wide and with errors of spacing less than o.0oI inch. This can, of course, be done, and I shall probably try it, but the simple oscillating bar suggested itself as an easy means of making a rigorous test of the method for the exacting task of observing the hydrogen flocculi against the brilliant disc of the sun.

Pasadena, California, GEORGE E. HALE. December 3 . 